\title{
ESPOCH's Education, Management and Research Achievements in Sustainable Development
}

\author{
Byron Vaca ${ }^{1,}$, Magdy Echeverría ${ }^{2}$, Rafael Cordova ${ }^{3}$ \\ ${ }^{1,2,3}$ Escuela Superior Politécnica de Chimborazo, Av. Panamericana Sur km 1 11/2 Riobamba, Chimborazo, Ecuador \\ * corresponding author: byron.vaca@espoch.edu.ec
}

\section{Article Info}

Received:

15 March 2021

Accepted:

25 May 2021

Published:

1 August 2021

DOI:

Presented in The $6^{\text {th }}$ International (Virtual) Workshop on UI GreenMetric World University Rankings (IWGM 2020)

\begin{abstract}
Although sustainable development focuses on continuing the progress of societies without putting future resources and the environment at risk, new technologies, political treaties and economic initiatives are not enough. In this context, the role of universities is fundamental in the formation of leaders that allow raising awareness in society, and in the implementation of pilot projects that can be quickly adjusted and scaled. ESPOCH forms sustainability competencies with a formal focus, by including courses in environmental sustainability within all study curricula, as well as with a non-formal focus through extracurricular activities such as tree planting, avoiding the use of private vehicles, among others. Regarding management, projects such as the replacement of campus luminaires with high-efficiency LED lights, reducing energy consumption from $69 \mathrm{kWh}$-day to 11.5 KWh-day and the construction of intelligent buildings that will allow efficient management of resources and spaces are being carried out. The feedback obtained from ESPOCH's participation in UI GreenMetric World University Rankings has allowed the university leaders, professors and students to identify the sectors that should be addressed as a priority and propose solutions to them considering sustainable development approaches.
\end{abstract}

\section{Keyword:}

sustainability, education for sustainability, energy efficiency, higher education, Latin America.

\section{Introduction}

Tackling climate change is becoming a ubiquitous issue in our current societies with several challenges that include the lack of information, limited resources and the denial of people, including country leaders [1]. Even when most countries in the world agreed on following an ambitious sustainable agenda, the strongholds providing the tools for proposing and applying sustainability strategies are the universities campuses [2].

The sustainable development goals (SDGs) establish the role of education as a fundamental tool to secure a prosperous future for humanity; through education the 17 goals can be achieved, including no poverty, zero hunger, and clean energy. The COVID-19 
pandemic has forced millions of students around the world into lockdown; however, by means of technology, online classes have been adopted worldwide, allowing students to keep on learning both formal classes and sustainable related courses [3]. There is evidence showing that students enrolled in fully online programs and receiving sustainability-related subjects get motivated and look for additional education in sustainable development [4].

University campuses are autonomous institutions, having their own rules and regulations; this makes possible to implement policies and programs with relative ease and allows the future dissemination to societies by means of the students, faculty, and staff [5]. For comparing the universities' accomplishments, most international rankings focus only on academic achievement; the UI GreenMetric World University Rankings' focus on sustainability has allowed Escuela Superior Politécnica de Chimborazo (ESPOCH) to pinpoint the strengths and weaknesses of the institutional policies [6]. In this paper, the achievements in education, management and research attained by ESPOCH in 2020 are described; even while teaching using online channels, actions for having a greener campus are carried out, with a positive feedback from the university community.

\section{Achievements in Education}

\subsection{Strengthening UI GreenMetric World University Rankings' indicators}

After receiving the official certificate from UI GreenMetric World University Rankings as the most sustainable university campus in Ecuador, a high-level meeting was organized including the president, vice-presidents and deans from ESPOCH as shown in Figure 1. The main goal of this event was showing the strengths of the university campus, but more importantly, the weaknesses were pointed out for finding green alternatives and fostering wider cooperation among the faculties and careers of ESPOCH.

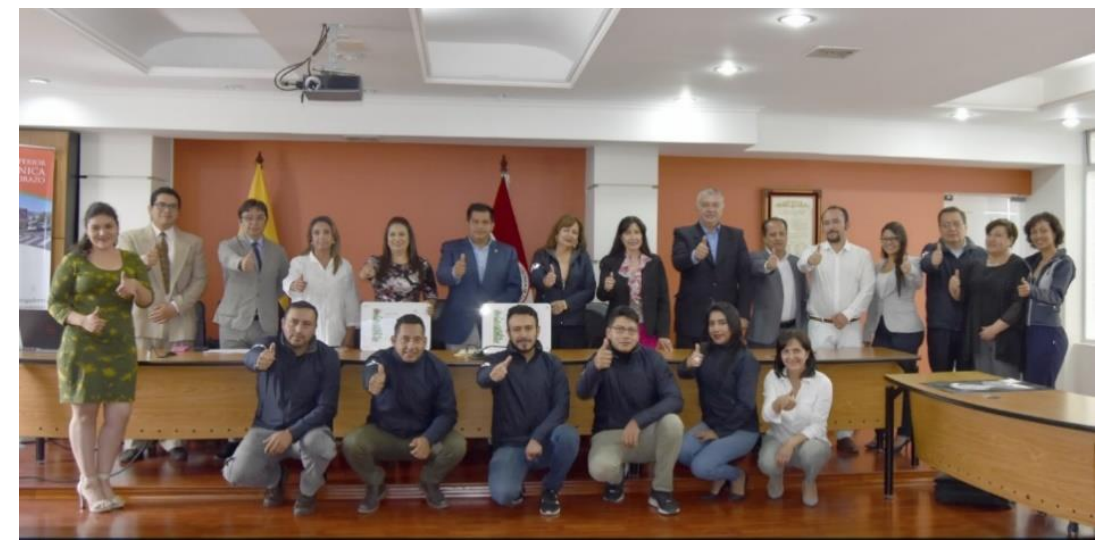

Figure 1. High level meeting for sharing indicators of strengths and weaknesses from ESPOCH regarding sustainability

\subsection{Environmental courses in all academic programs}

An important achievement regarding education is having the mandatory one-semester course entitled 'environmental sustainability' in all the academic programs at ESPOCH. By the end of this course students and faculty are encouraged to participate in non-formal activities such as tree planting (early 2020) and conferences on important dates such as the Earth Day which are showed in Figure 2; the conferences are available for the polytechnic community both live and as recordings. The main message conveyed by the presenters is that climate change, extreme climactic events, and ultimately, pandemics are caused by the 
generalized mistreatment that humans are subjecting the planet to; emphasis is made on turning destructive habits into sustainable ones.

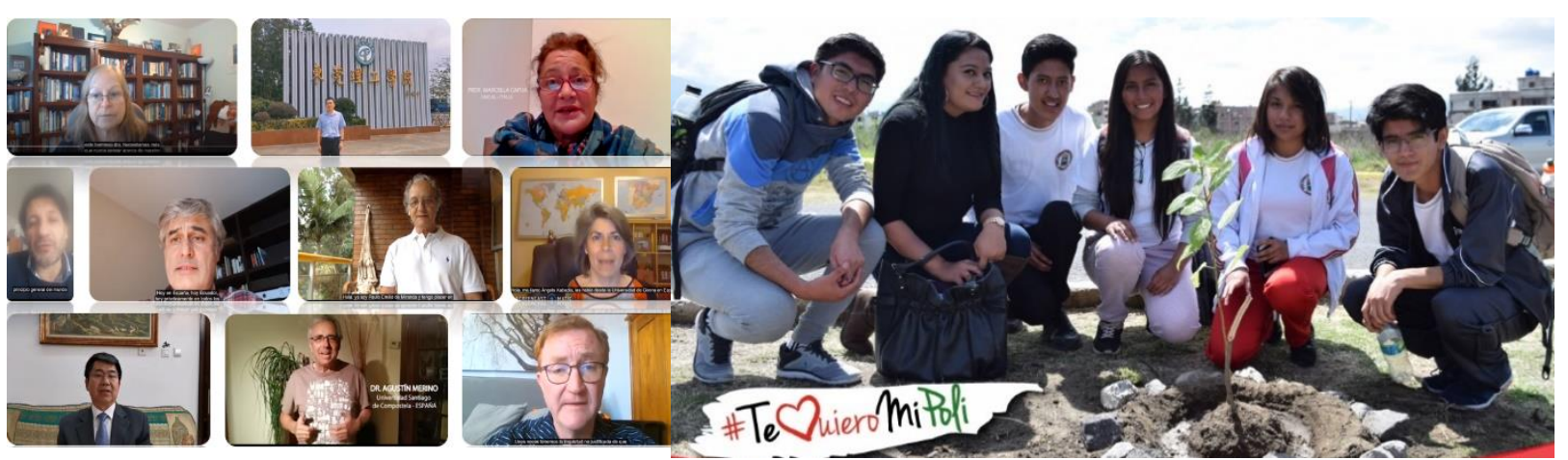

Figure 2. Extracurricular activities for the ESPOCH community: online conferences (left) and tree planting activities (right)

\section{Achievements in Management}

\subsection{Energy saving using LED luminaires}

Until early 2020, the luminaires in the main campus of ESPOCH (totaling 337) used to consume $69 \mathrm{kWh}$-day of energy; therefore, a complete upgrade of the system was required both for saving the environment and for bringing down the energy bills. LED luminaires were installed in the main campus as shown in Figure 3. A sharp decrease of almost $85 \%$ of the original energy consumption which is $11.5 \mathrm{kWh}$-day was obtained. Additional energy saving projects such us using heat pumps instead of fuel burners for heating the swimming pool water are being deployed.

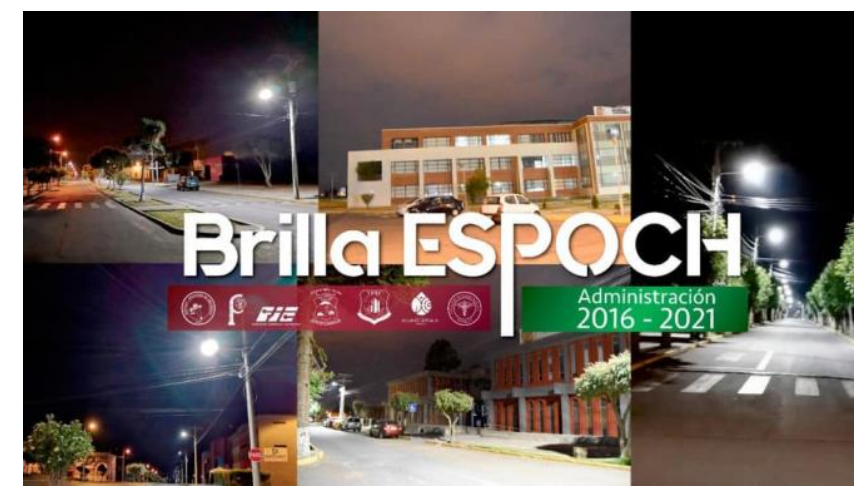

Figure 3. Campaign ESPOCH Shines for energy saving

\subsection{Enhanced bike paths in the campus}

The university campus already had a bike path connecting all the main buildings and shared spaces; however, because of the COVID-19 pandemic, the council of Riobamba decided to implement a bike path in the city consisting of two branches. ESPOCH has contributed to this effort by extending its inner path and connecting it to a city branch as depicted in Figure 4. Even when there are not in-person classes in the campus, essential management tasks, thesis works, and research projects are ongoing activities; the cityconnected university bike paths provide safe ways for students and staff so that they can commute keeping social distance and fostering sustainable transportation. 


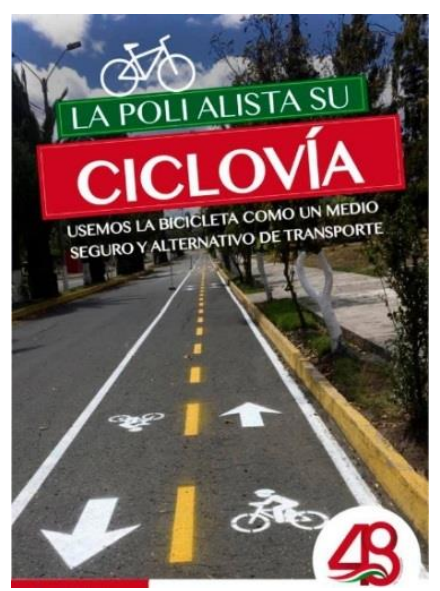

Figure 4. Bike paths on campus

\section{$4 \quad$ Achievements in Research}

\subsection{Design, fabrication and delivery of products against COVID-19}

The global emergency caused by the COVID-19 brought many challenges to Ecuador; no country in the world was prepared for facing it, but developing countries are having a tougher time. Higher education institutions such as ESPOCH used their infrastructure and human talent for carrying out initiatives that are helping to solve the needs of the healthcare sector, using locally available resources.

At the national level, from March to July, more than $22000 \mathrm{~L}$ of ethyl alcohol have been seized, which, have been processed into antibacterial gel by ESPOCH technicians for its use in hospitals, police institutions, etc. The artisanal liquor has a percentage of alcohol of $25 \%$ to $50 \%$, but its concentration must be rectified to $85 \%$ for sanitizing purposes; the whole process including adding camphor and methyl salicylate takes 4 days in average. More than $500 \mathrm{~L}$ of antibacterial gel have already been manufactured, which have been distributed in different public institutions.

In addition, 1700 face shields along with 10 cabins that allow doctors to be protected against COVID-19 have been delivered to the Ministry of Health, and funding has been sought for the manufacture of ten mechanical respirators, which have been endorsed by the doctors of the ICUs of the two main hospitals in the province of Chimborazo. Finally, a fully functioning laboratory containing the equipment for conducting PCR tests has been created; several pieces of equipment from specialized laboratories from ESPOCH have been put together in a specialized laboratory that already has official permission of the Ministry of Health.
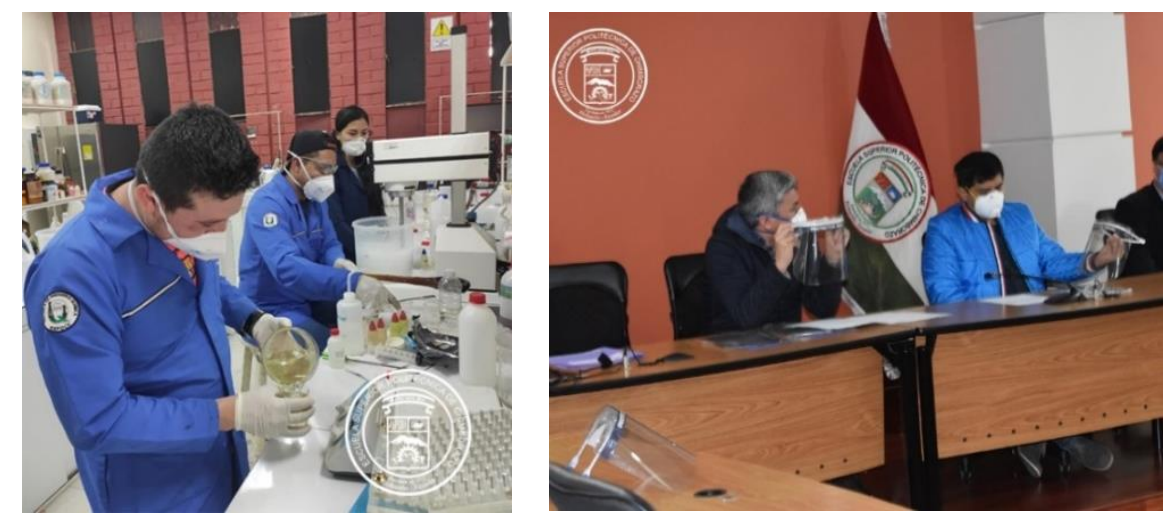

Figure 5. Production of hand sanitizer and face shields for helping fight COVID-19 


\section{Concluding Remarks}

Sustainable development is deeply engrained in the acts and policies emitted by the polytechnic council of ESPOCH, much of the initiatives are backed by the students who have showed energy and involvement into tree planting initiatives and climate change conferences; their insights are the cornerstone for the new projects. Regarding management, energy saving projects are being carried out for reducing the on-campus greenhouse gas production and for saving energy; the focus is becoming a greener campus. The COVID-19 pandemic has created many challenges to universities around the world; opportunities have appeared even more than challenges because now people are conscious that climate change consequences are troublesome for everybody. Easing the commute to ESPOCH for staff professors, researchers and students working on their thesis was achieved by means of extended bike paths in ESPOCH; the joint work with the city council allowed to blend the existing on-campus path with the new one created in the city of Riobamba. Finally, the research capabilities and human talent of ESPOCH allowed the conversion of low-quality alcohol into sanitizing gel and the fabrication of face shields by means of 3D printing; ESPOCH stands along with the Ecuadorian society through these challenging times.

\section{References}

1. Häkkinen K, Akrami N. Ideology and climate change denial. Pers Individ Dif 2014;70:625. doi:https://doi.org/10.1016/j.paid.2014.06.030.

2. United Nations. Transforming our World: The 2030 Agenda for Sustainable Development. 2015.

3. Sun L, Tang Y, Zuo W. Coronavirus pushes education online. Nat Mater 2020;19:687. doi:10.1038/s41563-020-0678-8.

4. Azeiteiro UM, Bacelar-Nicolau P, Caetano FJP, Caeiro S. Education for sustainable development through e-learning in higher education: Experiences from Portugal. J Clean Prod 2015;106:308-19. doi:10.1016/j.jclepro.2014.11.056.

5. Gornitzka $\AA$, Maassen P, Fumasoli T. University reform and institutional autonomy Åse Gornitzka, Peter Maassen and Tatiana Fumasoli 1. 2014.

6. UI GreenMetric World University Rankings. Fact File 2019 - Escuela Superior Politécnica de Chimborazo. Jakarta: 2019. 